\title{
Viabilidade econômica de espécies florestais e agrícolas em uma área de assentamento rural
}

As espécies florestais que compõem ecossistemas diversos proporcionam inúmeros benefícios ao meio ambiente, principalmente em relação à ciclagem de nutrientes, clima interno favorável, habitação de espécies (fauna e flora) e para a execução de diversas atividades humanas. Agricultores rurais associados à Movimento de Trabalhadores Rurais Sem Terra (MST) têm mantido como componente as espécies florestais com cultivos agrícolas, classificado como sistemas agroflorestais (SAFs). Assim, o presente artigo teve por objetivo realizar avaliação econômica - financeira de um SAF composto por 11 espécies de plantas, produzidas por uma família rural em área de assentamento. Para a execução desse estudo, foi realizado coleta de dados em campo, no Município de Santa Bárbara do Pará, região metropolitana de Belém. No presente trabalho, foram utilizados os seguintes parâmetros para análise: Relação Benefício-Custo (RBC), Valor Presente líquido (VPL) e Taxa Interna de Retorno (TIR). Os resultados obtidos mostraram que a viabilidade econômica do sistema agroflorestal apresentou valores de RBC (2.5), VPL (R\$20.905,55) e TIR (15\%). Logo, o sistema agroflorestal mostrou-se economicamente viável, propondo que o sistema pode ser adotado em propriedades rurais, gerando ao produtor renda por meio do consórcio florestal e agrícola.

\section{Economic viability of forest and agricultural species in a rural settlement area}

The forest species that make up diverse ecosystems provide numerous benefits to the environment, especially in relation to nutrient cycling, favorable indoo climate, habitation of species (fauna and flora) and the execution of various human activities. Rural farmers associated with the Landless Rural Workers Movement (MST) have maintained as a component forest species with agricultural crops, classified as agroforestry systems (SAFs). Thus, the objective of this article was to perform an economic and financial evaluation of an APS composed of 11 plant species produced by a rural family in a settlement area. To perform this study, field data were collected in the municipality of Santa Bárbara do Pará, metropolitan region of Belém. In the present work, the following parameters were used for analysis: Benefit-Cost Ratio (RBC), Net Present Value (NPV) and Internal Rate of Return (IRR). The results showed that the economic viability of the agroforestry system presented values of RBC (2.5), NPV (R \$20,905.55) and IRR (15\%). Thus, the agroforestry system proved to be economically viable, proposing that the system can be adopted on rural properties, generating income for the farmer through the forestry and agricultural consortium.

Keywords: Family farmers; Agroforestry systems; Amazon.

Topic: Ciências Florestais

Reviewed anonymously in the process of blind peer

Bruna Stefanny das Neves de Sousa

Universidade do Estado do Pará, Brasil

http://lattes.cnpq.br/4073199812914750

brunamonitoriaufra@gmail.com

Manoel Tavares de Paula

Universidade do Estado do Pará, Brasi

http://lattes.cnpq.br/6820319111894773

dpaulamt@hotmail.com

\section{Sibeli Borges}

Universidade Federal Rural da Amazônia, Brasil

http://lattes.cnpq.br/1970459593786308

belite.sb@gmail.com
Received: 01/10/2018

Approved: 01/11/2018

\author{
Altem Nascimento Pontes (iD) \\ Universidade Federal do Pará, Brasil \\ http://lattes.cnpq.br/5993352890364998 \\ http://orcid.org/0000-0002-9001-4603 \\ altempontes@hotmail.com
}

\section{Referencing this:}

SOUSA, B. S. N.; PAULA, M. T.; BORGES, S.; PONTES, A. N.. Viabilidade econômica de espécies florestais e agrícolas em uma área de assentamento rural. Revista Ibero-Americana de Ciências Ambientais, v.9, n.8, p.1-10, 2018. DOI: http://doi.org/10.6008/CBPC2179$\underline{6858.2018 .008 .0001}$ 


\section{INTRODUÇÃO}

A importância em se cultivar alimentos agrícolas com baixo grau de impacto ambiental é o que se pretende na garantia de preservar os recursos naturais, essenciais para manutenção dos ecossistemas e dos seres vivos que o compõem, características essas que visam os sistemas agroflorestais (SAFs). Segundo Macedo (2013), a grande perda dos recursos naturais na Amazônia está relacionada ao desmatamento, proveniente do uso extensivo de terras e tecnologias inapropriadas. Os sistemas agroflorestais (SAFs), porém, têm sido uma alternativa fundamental na recuperação de áreas já desmatadas (PORRO, 2009).

De acordo, com Woods (2003), os SAFs têm sua origem fundamentada em práticas de cultivo agrícola advindos de povos antigos, com a principal finalidade de proporcionar condições ideais ao solo para plantio em diferentes arranjos de produção. Ribaski (2012) relata que esses sistemas são formas de uso ou manejo da terra, nos quais se combinam espécies arbóreas (frutíferas e/ou madeireiras) com cultivos agrícolas e/ou criação de animais, de forma simultânea ou em sequência temporal e que promovem benefícios econômicos e ecológicos. Além disso, permite realizar o uso em diferentes modalidades como: sistema agroflorestal, sistema silvipastoril e o mais completo deles, o sistema agrosilvipastoril (SOUZA et al., 2007).

A presença de árvores em SAFs, além de exercer importância nos sistemas de produção, é fundamental para a formação de paisagens e para o fornecimento de sombra. Conforme Macedo (2013), recentemente o Centro Mundial Agroflorestal (Icraf), sediado no Kenya, na África, adotou a seguinte definição: Sistema Agroflorestal ou Agrossilvicultura, que é a integração de árvores em paisagens rurais produtivas. Com a integração de animais no sistema, as árvores também são essenciais para o fornecimento de sombra, proporcionando conforto térmico animal (MARTIN, 2002).

$\mathrm{Na}$ tentativa de manter a qualidade do solo, agricultores integrantes ao Movimento dos Trabalhadores Rurais Sem-Terra (MST), passaram a utilizar os sistemas agroflorestais como forma de obterem benefícios ambientais, sociais e econômicos. Conforme Junqueira et al. (2013), nos últimos anos, em meio à crise socioeconômica e ambiental, os assentamentos rurais vêm se configurando como importantes conquistas dos movimentos sociais. Contudo, o aumento da ocupação desses territórios de construção de novas relações sociais e com os recursos naturais, é ameaçada pelos passivos ambientais deixados pelos latifúndios monocultores (RAMOS FILHO et al., 2006).

Utilizado como forma de recuperação de área degradas, os sistemas agroflorestais proporcionam melhorias ao solo para fins agropecuário e florestal. Vaz (2002) menciona que o sistema é considerado adequado à restauração de áreas degradadas, pois favorece a estruturação do solo e eleva os níveis de nutrientes do solo em função de uma maior eficiência de ciclagem de nutrientes, promovida pelas raízes e pelo acúmulo de serapilheira. Devido aos tantos benefícios que o sistema proporciona, sua diversificação promove novas opções de mercado, tornando-se uma estratégia contra possíveis entraves econômicos, podendo ser um diferencial competitivo do agronegócio brasileiro, tanto para o setor pecuário, quanto para o setor de base florestal (SANTOS et al., 2014).

Diante do exposto, o presente trabalho objetivou realizar a avaliação econômica do sistema 
agroflorestal, implantado com a finalidade de recuperação da área degradada, para fins agrícolas em um assentamento rural, no Município de Santa Bárbara (PA).

\section{MATERIAL E MÉTODOS}

O presente trabalho foi realizado na Associação dos Trabalhadores Rurais Agroecológico Expedito Ribeiro (ATRAER) no município de Santa Bárbara do Pará. O município (figura 1) tem como coordenada geográfica de $01^{\circ} 13^{\prime} 25^{\prime \prime}$ S e longitude de $48^{\circ} 17^{\prime} 40^{\prime \prime}$ W, com altitude de 21 metros. Sua população estimada para 2017 é de 20.492 habitantes, possuindo área territorial de $278.154 \mathrm{~km}^{2}$ (IBGE, 2016).

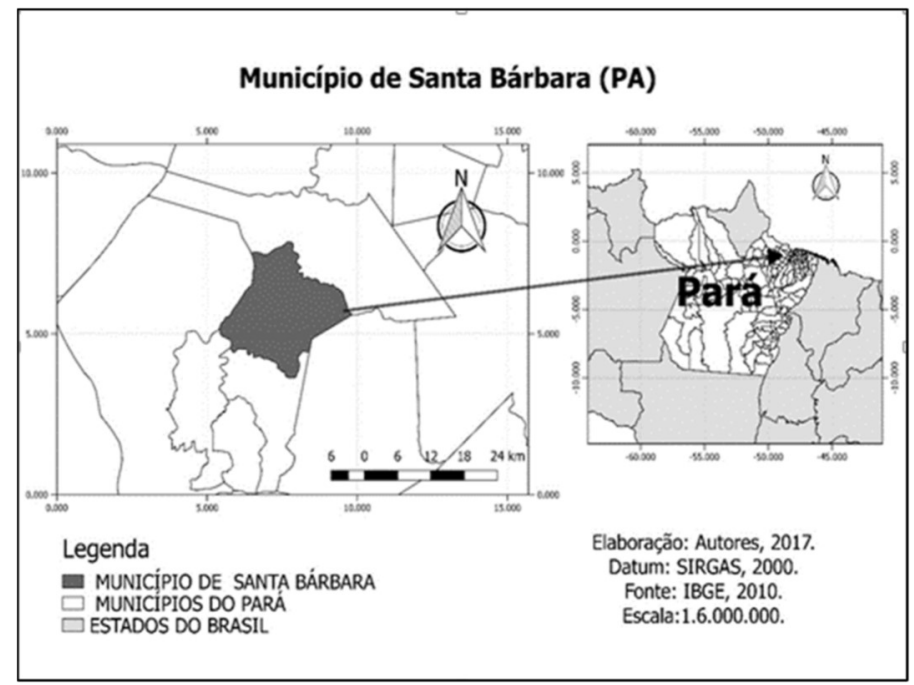

Figura 1: Localização da área de estudo.

A climatologia é classificada 'Am', segundo Köppen e Geiger, tendo temperatura média de $26^{\circ} \mathrm{C}$ e pluviosidade chega a ultrapassar os $2.550 \mathrm{~mm}$ anuais. A topografia caracteriza-se por um relevo predominantemente plano, com tipo Glei Pouco Húmico Hidromórfico (SANTOS et al., 2006). A análise econômica foi realizada para o período de 20 anos em área de 1 ha do sistema agroflorestal constituído por 11 espécies de plantas, dentre elas florestais e agrícolas. Quanto aos procedimentos técnicos metodológicos, esta pesquisa tem caráter bibliográfico e se caracteriza como estudo de campo, com realização de visitas in loco para levantamento de dados.

A área utilizada para estudo possui tamanho de $48 \mathrm{~m}^{2}$ de largura $\times 100 \mathrm{~m}^{2}$ de comprimento, nessa área estão presentes as espécies analisadas, conforme a tabela 1, além da presença de criação de pequenos animais (aves e suínos) e a casa onde o produtor convive com sua família. Dentre os produtos obtidos, tem-se a comercialização dos frutos e/ou da madeira. 0 espaçamento utilizado foi fornecido pelo produtor, mas para maior confiabilidade dos dados, foi realizada a medição dos espaçamentos no campo de todas as plantas.

Tabela 1: Caracterização das espécies estudadas na pesquisa, que integram o sistema agroflorestal no assentamento rural Expedito Ribeiro (PA)

\begin{tabular}{|c|c|c|c|c|c|}
\hline Ipé & Tabebuia alba(Cham.) Sandwith & $10 \times 10$ & 1 & $10.26 \%$ & Ipé \\
\hline $\mathrm{Nim}$ & Azadirachta indica A. Juss. & $10 \times 12$ & 1 & $5.13 \%$ & $\mathrm{Nim}$ \\
\hline Freijó & Cordia goeldiana Huber & $10 \times 10$ & 1 & $12.82 \%$ & Freijó \\
\hline Castanheira & Bertholletia excelsa Bonpl. & $12 \times 12$ & 2 & $3.85 \%$ & Castanheira \\
\hline Bacupari & Garcinia brasiliensis Mart. & $6 \times 6$ & 1 & $5.13 \%$ & Bacupari \\
\hline Rambutã & Nephelium lappaceum L. & $6 \times 6$ & 1 & $10.26 \%$ & Rambutã \\
\hline
\end{tabular}


A distribuição das espécies, conforme ilustra a figura 2, segue um método empírico adotado pelo próprio morador da propriedade. Ressalta-se a importância da assistência técnica na localidade, que contribuíram para o planejamento do SAF, através do fornecimento de informações sobre manejo para a realização do cultivo. É também relevante mencionar a busca de conhecimento pelos próprios produtores de como manejar sua produção, em institutos públicos ou via pesquisa na internet nos centros urbanos.

\begin{tabular}{|c|c|c|c|c|c|}
\hline *⿻丷木 & 楼 & * & $*$ & $x$ & $x$ \\
\hline$*$ & 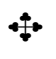 & 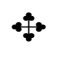 & $x$ & $x$ & $x$ \\
\hline * & $\dot{q}$ & \&) & $x$ & $x$ & $x$ \\
\hline * & 橉 & $q$ & $x$ & $x$ & $x$ \\
\hline * & $*$ & 解 & $*$ & $*$ & 2 \\
\hline * & 睡 & $*$ & 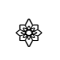 & * & 的觔 \\
\hline$*$ & $\nLeftarrow$ & \&6 & $*$ & \& & $x$ \\
\hline 䊑 & \&) & $q$ & 2 & 80 & $x$ \\
\hline 类 & * & * & $x$ & 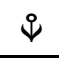 & $x$ \\
\hline
\end{tabular}

Figura 2: Croqui do sistema agroflorestal estudado no assentamento rural no município de Santa Barbara (PA).

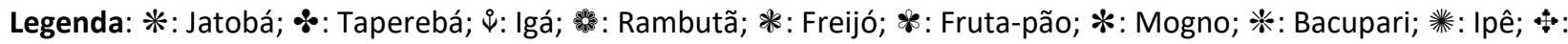
Castanheira; : Nim; e x: Perda de plantas.

Um dos principais fatores determinantes que influenciam na construção de um sistema agroflorestal é a obtenção do material que irá compor o mesmo, com isso, o custo e a oferta de mudas mais acessíveis são fundamentais. Os valores referentes aos preços de mudas atualizados (tabela 2) foram levantados conforme o mês de dezembro de 2017, no mercado de mudas Amazonflora, localizado na BR316 em Marituba-Pará.

Tabela 2: Preços de mudas comercializados na Região Metropolitana de Belém, no período dezembro de 2017.

\begin{tabular}{|c|c|c|c|}
\hline Mudas & Preço da Unidade (R\$) & Densindade (plantas.ha $\mathbf{~}^{-1}$ ) & Total \\
\hline Jatobá & 5,00 & 5 & 25,00 \\
\hline Taperebá & 5,00 & 4 & 20,00 \\
\hline Ingá & 7,00 & 4 & 28,00 \\
\hline Fruta pão & 10,00 & 2 & 20,00 \\
\hline Ipé & 5,00 & 4 & 20,00 \\
\hline Nim & 10,00 & 2 & 20,00 \\
\hline Freijó & 4,00 & 5 & 20,00 \\
\hline Castanheira & 10,00 & 3 & 30,00 \\
\hline Bacupari & 8,00 & 2 & 16,00 \\
\hline Rambutã & 8,00 & 4 & 32,00 \\
\hline Mogno Brasileiro & 12,00 & 4 & \\
\hline Total & - & 39 & 38,00 \\
\hline
\end{tabular}

Para a realização dos cálculos dos indicadores financeiros, foi utilizado a Planilha de Análise financeira de sistemas produtivos integrados (EMBRAPA, 2014). A princípio, os parâmetros gerais (tabela 3) foram estabelecidos para as possíveis análises, sendo a taxa de financiamento estipulada de acordo com o plano de financiamento do Banco da Amazônia do Programa Nacional de Fortalecimento da Agricultura Familiar (PRONAF), para o setor florestal. A tabulação dos dados e cálculo dos critérios de avaliação econômica foi também constatada e confirmada pelas fórmulas de indicadores financeiros, sendo os mesmos muito utilizado na literatura. 
Tabela 3: Parâmetros econômicos instituídos para determinação dos dados.

\begin{tabular}{|c|c|c|c|}
\hline \multicolumn{2}{|c|}{ Parâmetros } & \multicolumn{2}{|c|}{ Critérios } \\
\hline \multicolumn{2}{|c|}{ Valor da Mão de Obra (diária): } & \multicolumn{2}{|c|}{$\mathrm{R} \$ 50,00$ homem/dia } \\
\hline \multicolumn{2}{|c|}{ Valor da Hora de Máquina (com operador): } & \multicolumn{2}{|c|}{$\mathrm{R} \$ 100,00$ hora/máquina } \\
\hline \multicolumn{2}{|c|}{ Taxa de Juros (financiamento): } & \multicolumn{2}{|c|}{$2.5 \%$ ao ano } \\
\hline \multicolumn{2}{|c|}{ Taxa Mínima de Atratividade: } & \multicolumn{2}{|c|}{$2.5 \%$ ao ano } \\
\hline \multicolumn{2}{|c|}{ Taxa de Desconto do Projeto: } & \multicolumn{2}{|c|}{$2.5 \%$ ao ano } \\
\hline \multicolumn{2}{|c|}{ Área do Módulo de Produção: } & \multicolumn{2}{|c|}{$1 \mathrm{ha}^{-1}$} \\
\hline \multirow{2}{*}{ Espécies } & \multicolumn{3}{|c|}{ Preço de Venda dos Produtos } \\
\hline & Produtos & Unidade & Preço \\
\hline Jatobá & Madeira & $\mathrm{m}^{3}$ & $\mathrm{R} \$ 235,00$ \\
\hline Taperebá & Frutos & $\mathrm{kg}$ & $\mathrm{R} \$ 2,00$ \\
\hline Ingá & Adubo verde & --- & --- \\
\hline Fruta pão & Frutos & $\mathrm{kg}$ & $\mathrm{R} \$ 2,00$ \\
\hline Ipé & Madeira & $\mathrm{m}^{3}$ & $\mathrm{R} \$ 700$ \\
\hline $\mathrm{Nim}$ & Inseticida natural & --- & --- \\
\hline Freijó & Madeira & $\mathrm{m}^{3}$ & $\mathrm{R} \$ 200,00$ \\
\hline Castanheira & Frutos & $\mathrm{kg}$ & $\mathrm{R} \$ 10,00$ \\
\hline Castanheira & Madeira & $\mathrm{m}^{3}$ & $\mathrm{R} \$ 300,00$ \\
\hline Bacupari & Madeira & $\mathrm{kg}$ & $\mathrm{R} \$ 5,00$ \\
\hline Rambutã & Frutos & $\mathrm{kg}$ & $\mathrm{R} \$ 7,00$ \\
\hline Mogno Brasileiro & Madeira & $\mathrm{m}^{3}$ & $\mathrm{R} \$ 1.500,00$ \\
\hline
\end{tabular}

\section{Fórmulas para avaliação econômica}

Para avaliação econômica foi utilizado dados de resultado de análises de indicadores financeiros. Segundo Dossa (2000), esses indicadores podem ser obtidos pelo Valor Presente Líquido (VPL), Relação Custo/Benefício (RB/c) e Taxa Interna de Retorno (TIR). A obtenção de dados dos valores referente a insumos e serviços, foram aplicados questionários semi-estruturados em campo, de forma direta aos trabalhadores rurais do assentamento, com intuito de estimar valores de custos de receitas e insumos.

O valor Presente Líquido (VPL) é considerado uma via de alternativa eficaz para avaliação de investimentos, pois tem o propósito de estimar, a partir da utilização de uma taxa mínima do capital, o valor atual do fluxo de caixa. Ressalta-se que, para se calcular o Valor Presente Líquido, faz-se necessário trazer os valores de cada período anteriores para o valor atual, tanto dos investimentos quanto dos custos e receitas (SANTANA, 2005). Foi calculado de acordo com a fórmula matemática predisposta na figura 3.

$$
\mathrm{VLP}=\sum_{\mathrm{j}=0}^{\mathrm{n}} \mathrm{R}_{\mathrm{j}}+(1+\mathrm{i})^{\mathrm{j}}-\sum_{\mathrm{j}=0}^{\mathrm{n}} \mathrm{C}_{\mathrm{j}}+(1+\mathrm{i})^{\mathrm{j}}
$$

Figura 3: Fórmula matemática que calcula o VPL. Legenda: $\mathrm{R}_{\mathrm{j}}$ : Receitas do projeto no ano j; $\mathrm{C}_{\mathrm{j}}$ : Custo do projeto no ano j; n: Vida útil do projeto; VPL >0: Empreendimento é viável economicamente (Receita > Custo); VPL < 0 - O:

Empreendimento é inviável (Receita < Custo); VPL = 0: Não há lucro, receitas são suficientes para cobrir as despesas.

A Taxa Interna de Retorno (TIR) servirá para igualar o valor presente dos ganhos futuros do projeto em relação aos gastos obtidos nos mesmos (LYRA et al., 2010). Logo, um projeto só será viável se tiver a TIR superior à taxa mínima. Para tal devemos calcular a taxa que zera o VPL. No entanto, ressalta-se que o cálculo da TIR não pode ser calculado tão facilmente, pois não conseguimos isolar i (taxa) da equação acima e colocar em evidência, para isso devemos aplicar o método de aproximações sucessivas ou método numérico de tentativas e erros, logo devemos atribuir um valor para i e calcular o VPL, se VPL for um valor alto atribuímos um valor maior para i, fazemos isso até que VPL seja zero, conforme se propôs na figura 4 
(ROSS et al., 1995).

$$
\mathrm{VPL}=0=\mathrm{C}_{\mathrm{O}}+\sum_{i=1}^{t} \frac{C_{i}}{(1+r)^{i}}
$$

Figura 4: Valor de VPL $=0$

A Relação Benefício Custo (RB/c) é caracterizada por verificar a situação dos benefícios do projeto, se estes estão maiores do que os custos, pois sua viabilidade econômica quando os investimentos a RB/c maior que 1 , indicando desta forma se as receitas são maiores que os custo (SANTANA, 2005). Na determinação da RB/c (figura 5). A tabulação dos dados coletados a partir de estimativas de custo de implantação do SAF e os cálculos dos critérios de avaliação econômica foram organizados em uma planilha do Microsoft Excel 2013.

$$
\text { Relação } B / C=\frac{\sum_{j=0}^{n} R_{j} /(1+i)^{j}}{\sum_{j=0}^{n} C_{j} /(1+i)^{i}}
$$

Figura 5: Determinação da RB/c

\section{RESULTADOS}

A partir dos dados obtidos pode-se observar que o custo de serviços e insumos requerido para a implantação do Sistema Agroflorestal em 1 hectare, estão relacionadas as atividades de mão-de-obra, que requer serviços para limpeza da área, roçagem, aração, gradeação, aplicação de fertilizantes e manutenção (planta/solo). Assim como, o custo para obtenção de insumos agrícolas, obtenção de mudas, adubos químicos e orgânicos, calcário, fungicidas, inseticidas e transporte (tabela 4).

Tabela 4: Custos de produção (R\$) relativos a 1ha de SAF estudado na pesquisa.

\begin{tabular}{|l|c|c|c|c|c|c|}
\hline & Ano 0 & 1 a 5 Anos & 6 a 10 Anos & 11 a 15 Anos & 16 a 20 Anos & Percentual \\
\hline Serviços & 1800,00 & 20078,08 & 19900,00 & 19350,00 & 16650,00 & $93 \%$ \\
\hline Insumos & 593,00 & 1213,50 & 1132,00 & 1132,00 & 1135,00 & $7 \%$ \\
\hline Total & 2393,00 & 21291,58 & 21032,00 & 20482,00 & 17785,00 & $100 \%$
\end{tabular}

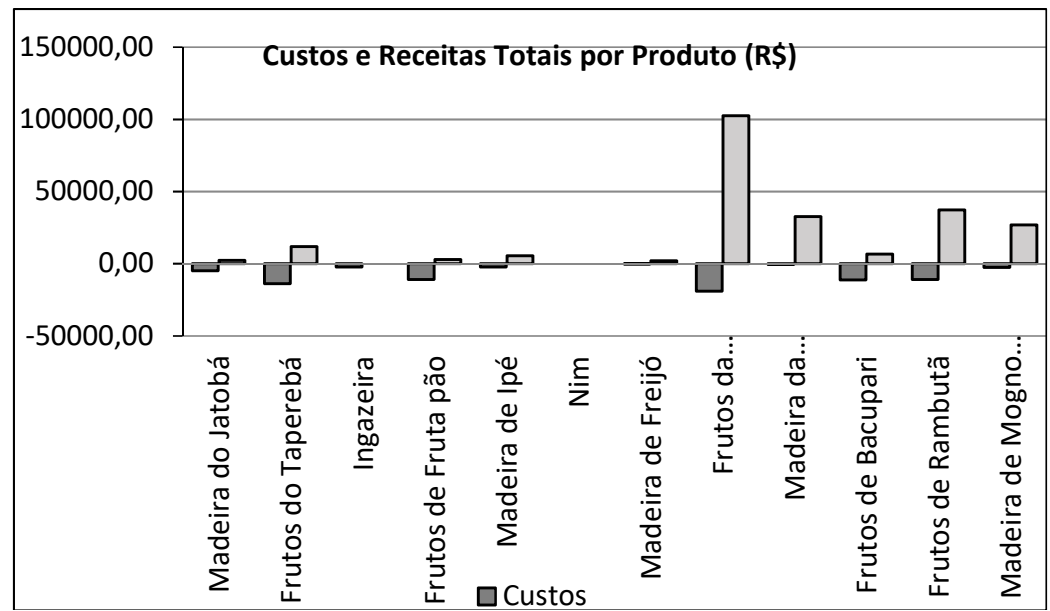

Figura 1: Custos e receitas totais de cada produto do sistema agroflorestal estudado, no assentamento rural Expedito Ribeiro (PA).

Pode-se também verificar a relação do custo e receita de cada cultura integrante no sistema agroflorestal (figura 6). Nota-se que dentre os produtos obtidos no sistema agroflorestal, a castanheira foi que proporcionou maior rendimento em relação a receita e custo, seguido das culturas de Rambutã e 
Mogno Brasileiro, em comparação as demais culturas. Porém, o Nim não apresentou valores de receita, devido já está no terreno há anos, foi deixado com a finalidade de proporcionar benefícios ambientais.

A figura 2 mostra a distribuição dos custos de mão-de-obra e insumos de cada cultura presente no SAF estudado. Como pode ser observado as culturas do Taperebazeiro e da castanheira, apresentaram maiores custos, em relação as demais culturas estudadas no sistema, ambas com custos superiores entre $\mathrm{R} \$ 10.000,00$ (mão-de-obra e insumos).

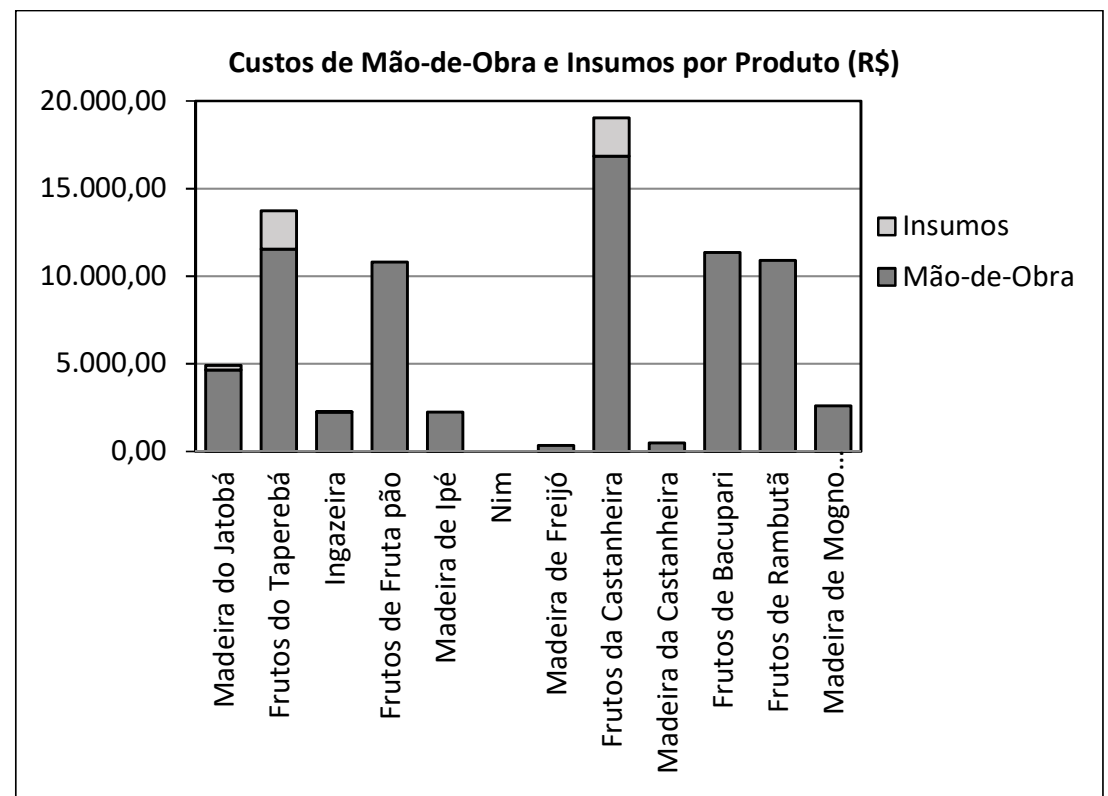

Figura 2: Custos de mão-de-obra e insumos de cada produto do sistema agroflorestal estudado, no assentamento rural Expedito Ribeiro (PA).

De acordo, com os dados de custos e receitas foi elaborada uma planilha com o fluxo de caixa para a implantação do SAF, por período de ocorrência de 20 anos, com uso de um orçamento unitário em $\mathrm{R} \$ 1,00$ (tabela 5). Conforme os dados obtidos, pode-se verificar que na formação do fluxo de caixa, as despesas de investimento com a implantação e na manutenção do ano 0 até o ano 5, apresenta Benefício líquido negativo, uma vez que a produção ainda não cobre os custos. Vale ressaltar que as informações usadas para a avaliação econômica de um projeto são projeções para o futuro de um possível fluxo de caixa e, desta forma, estão sujeitas a erros e variações (CARVALHO et al., 2014). Os resultados dos principais indicadores econômicos são propostos na tabela 6, e a curva de VPL, trazido pelo gráfico 1, para o sistema de produção (SAF) em 1 ha $^{-1}$, à taxa de $2,5 \%$ ao ano.

Tabela 5: Fluxo de caixa para avaliação econômica em $\mathrm{R} \$$ na implantação de 1 ha de SAF.

\begin{tabular}{|c|c|c|c|c|c|}
\hline Especificação & Ano 0 & 1 a 5 Anos & 6 a 10 Anos & 11 a 15 Anos & 16 a 20 anos \\
\hline I - Entrada & & & & & \\
\hline Valor da produção & 00,00 & 1550,00 & 24730,00 & 46060,00 & 145750,00 \\
\hline Total (A) & 00,00 & 1550,00 & 24730,00 & 46060,00 & 145750,00 \\
\hline II-Saída & & & & & 19350,00 \\
\hline a) Serviços & 1800,00 & 20078,08 & 19900,00 & 1900,00 \\
\hline b) Insumos & 593,00 & 1213,50 & 1132,00 & 1132,00 & 1135,00 \\
\hline Total (B) & 2393,00 & 21291,58 & 21032,00 & 20482,00 & 17785,00 \\
\hline III- Benefício & & & & 25578,00 & 127965,00 \\
\hline Liquido (A-B) & $-2393,00$ & $-19741,58$ & 3698,00 & & \\
\hline
\end{tabular}


Tabela 6: Indicadores de decisão econômico-financeira para a implantação do SAF.

\begin{tabular}{|c|c|}
\hline Indicadores & Total \\
\hline Relação Benefício/Custo & 2,4 \\
\hline Valor Presente Líquido & $89.473,70$ \\
\hline Taxa Interna de Retorno & $15 \%$ \\
\hline
\end{tabular}

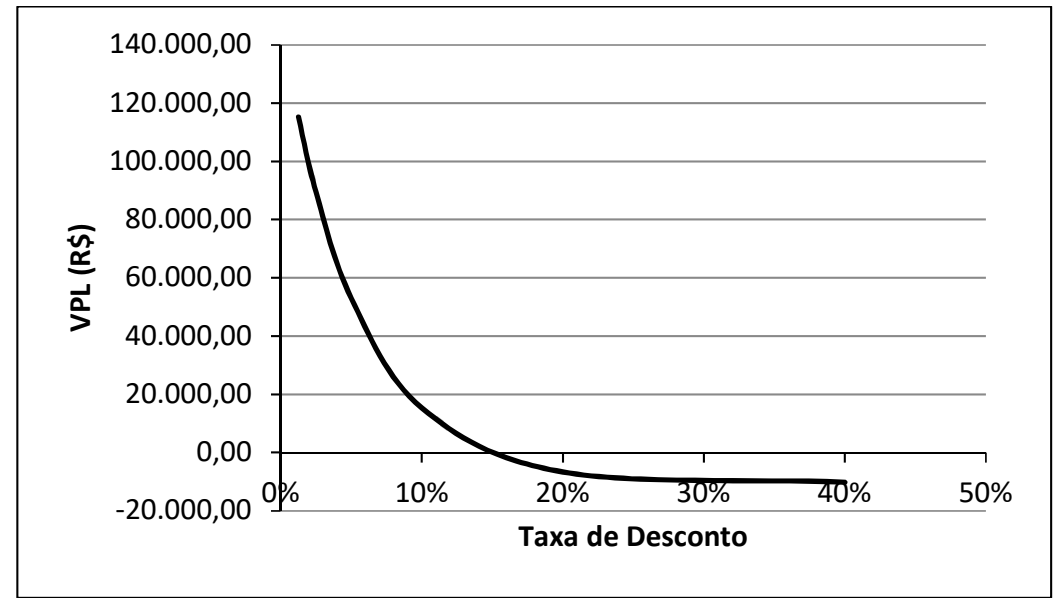

Gráfico 1: Curva de sensibilidade do VPL.

\section{DISCUSSÃO}

Considerando uma estimativa de 20 anos, todos os custos fixos foram contemplados de acordo com a atividade desenvolvida. Logo, podemos observar que os resultados apresentados, demonstraram que o item que mais onerou de forma significante no custo de produção da implantação, foi o custo com os serviços em relação aos insumos. Dados semelhantes também foram encontrados em estudos de viabilidade econômica, em um sistema agroflorestal composto pelas culturas de paricá, cupuaçu, feijãocaupi e mandioca, tendo o item serviços o fator mais relevante na composição dos custos de produção do sistema (PALHETA et al., 2014).

Segundo Euler et al. (2013), o motivo da castanheira em proporcionar maiores benefícios econômicos, seria por ser uma cultura de grande ocorrência na região Amazônica, muito presente em áreas de terra firme, servindo como importante fonte de renda para diversas famílias extrativistas. Em relação ao cultivo da rambuteira, ainda é considerada uma atividade recente no Brasil, contudo, os plantios comerciais de rambutã são abundantes e restritos aos Estados da Bahia, Pará e São Paulo (SACRAMENTO et al., 2014).

De acordo com Siqueira et al. (2000), normalmente, o plantio comercial das culturas perenes de castanheiras tem elevado custo de implantação e retorno lento do capital investido, tornando-se indispensável a realização de um estudo econômico prévio, bem elaborado, para reduzir os riscos do investimento. Com relação a produção do Taperebazeiro, apesar do custo alto durante a implantação no SAF, a comercialização dos frutos apresenta mercado promissor na Região Amazônica, uma vez que ausência de pomares comerciais, as agroindústrias são totalmente dependentes da produção extrativista, que é sazonal e insuficiente para a operacionalização das agroindústrias de polpa (SOUZA, 2005).

Com base no plantio do Mogno Brasileiro, é uma espécie de grande interesse econômico, devido a sua excelente aceitação pelos mercados regional, interestadual e internacional, pois sua madeira é de alta qualidade para a indústria, sendo utilizado no mundo todo para a confecção de mobiliários de luxo (LORENZI, 2002). Entretanto, é relevante mencionar que a sua comercialização desde não certificada, é 
proibida por ser uma madeira protegida por lei e sofre com alta incidência de pragas (COUTO et al., 2004).

A ingazeira e o Nim, chamam atenção pelos resultados, devido as mesmas não serem de interesse econômico para o produtor, porém exercem função importante para o sistema agroflorestal, tendo a ingazeira serventia de adubo verde e o Nim como inseticida natural. A ingazeira no sistema agrossilvicultural, conforme Sousa et al. (2007), tem como finalidades, além da adubação verde como provedora de nutrientes, é produtora de biomassa, fornecedora de sombra para as culturas perenes no sistema. O Nim também proporciona biomassa aos sistemas agroflorestais; no entanto, a sua principal propriedade mais conhecida está relacionada como agente de inseticida natural, que gera esterilidade dos insetos, repelência e inanição alimentar (GARCIA, 2003; SOARES, 2006; SOUZA, 2011).

A viabilidade econômica da implantação do SAF pelo método do valor presente líquido (VPL) é indicada pela diferença positiva entre receitas e custos, atualizados de acordo com a taxa de desconto de 2,5\% ao ano. OVPL obtido foi de R\$89.473/ha. Neste caso o VLP é positivo, a RB/C é maior que a unidade e a TIR é maior que a taxa mínima de atratividade de $2,5 \%$ ao ano.0 resultado mostra que para cada $\mathrm{R} \$ 1,00$ investido no empreendimento à taxa $12 \%$ ao ano, retorna bruto $R \$ 2,50$ ou líquido $R \$ 1,50$, atestando a viabilidade do Sistema Agroflorestal. Os valores de VPL, TIR e R B/C demonstram viabilidade econômica para a implantação do SAF dentro de um enfoque econômico.

De acordo, com análise da curva de sensibilidade mostra que a TIR (taxa interna de retorno) de $15 \%$, ou seja, de forma simples e objetiva, pode-se observar nesse gráfico, que o VPL é zero para a taxa próxima de 15\%, que sendo maior que a TMA (taxa mínima de atratividade) indica que o investimento é financeiramente atrativo.

\section{CONCLUSÃO}

Todos os indicadores utilizados nesta avaliação econômica atestam viabilidade do sistema agroflorestal, podendo ser melhorada com implementação de espécies anuais nos primeiros anos, para que possam entrar em produção nesse período visando amortecer os custos. Podemos afirmar que os sistemas agroflorestais podem ser adotados nas propriedades em áreas de assentamento rural, podendo gerar maior renda ao produtor graças ao consórcio agrícola. Sua maior ou menor viabilidade econômica irá depender de um manejo mais intensificado na área para a produção agrícola e de preços satisfatórios para venda no mercado. Por fim, recomenda-se continuidade em pesquisas como esta na região, com o intuito de avaliar o desenvolvimento dessas áreas a longo prazo, que permitam avaliar a produtividade da área para cada cultura praticada, fazendo comparações com as médias de produção encontradas na região e analisando o máximo de retorno (produtivo e financeiro) que pode ser esperado por hectare plantado.

\section{REFERÊNCIAS}

CARVALHO, C. R. F.; PONCIANO, N. J.; SOUZA, P. M.; SOUZA, C. L. M.; SOUSA, E. F.. Viabilidade econômica e de risco da produção de tomate no município de Cambuci/RJ, Brasil. Ciência Rural, Santa Maria, v.44, n.12, p.2293-2299, 2014. DOI: http://doi.org/10.1590/0103-8478cr20131570

COUTO, L. C.; COUTO, L.; WATZLAWICK, L. F.; CAMÂRA, D..
Vias de valorização energética da biomassa. Biomassa e Energia, v.1, n.1, p.71-92, 2004.

DOSSA, D.; CONTO, A. J.; RODIGHERI, H.; HOEFLICH, V. A.. Aplicativo com análise de rentabilidade para sistemas de produção de florestas cultivadas e de grãos. Colombo: Embrapa, 2000. 
EMBRAPA. Empresa Brasileira de Pesquisa Agropecuária. Análise financeira de sistemas produtivos integrados. Colombo: Embrapa, 2014.

EULER, A. M. C.; BERNADELLI, A.; SOUSA, W. P.; CARVALHO, A. C. A.. Viabilidade econômica da produção de castanhado-Brasil no território Sul do Amapá, Brasil. In: SIMONIAN, L. T. L.; COSTA, A. J. S.; BAPTISTA, E. R.. Escudo Guianês, biodiversidade, conservação dos recursos naturais e cultura. Belém: NAEA, 2013. p.331-348.

GARCIA, F.. Produtos naturais como inseticidas e repelentes de insetos. In: JORNADA CATARINENSE DE PLANTAS MEDICINAIS, 4. Anais. Itajaí: ACPM, 2003.

IBGE. Instituto Brasileiro de Geografia Estatística. Cidades: Santa Bárbara: População. Rio de Janeiro: IBGE, 2017.

JUNQUEIRA, A. C.; SCHLINDWEIN, M. N.; CANUTO, J. C.; NOBRE, H, G.; SOUZA, T. J. M.. Sistemas agroflorestais e mudanças na qualidade do solo em assentamento de reforma agrária. Revista Brasileira de Agroecologia, v.8, n.1, p.102-115, 2013.

LORENZI, H.. Árvores brasileiras: manual de identificação e cultivo de plantas Arbóreas do Brasil. 4 ed. São Paulo: Instituto Plantarum, 2002.

LYRA, G. B.; PONCIANO, N. J.; SOUZA, P. M.; SOUSA, E. F.. Viabilidade econômica e risco do cultivo de mamão em função da lâmina de irrigação e doses de sulfato de amônio. Acta Scientiarum Agronomy, v.32, n.3, p.547-554, 2010. DOI: http://doi.org/10.4025/actasciagron.v32i3.2451

MACEDO, J. L. V.. Sistemas Agroflorestais: princípios básicos. Manaus: Instituto Amazônia, 2013.

MARTIN, G. O.. Mantenga la sombra en sus potreros y reduzca el estrés animal. Revista producción, 2002.

PALHETA, I, C.; GOMES, C. A. S.; LOBATO, G. J. M.; PAULA, M. T.; PONTES, A. N.. Viabilidade econômica de um sistema agroflorestal no Município de Santa Bárbara-PA. Revista Enciclopédia Biosfera, Goiânia, v.10, n.19, 2014.

PORRO, R.. Alternativa Agroflorestal na Amazônia em transformação. Brasília: Embrapa, 2009.

RAMOS FILHO, L. O.; PELLEGRINI, J. B. R.. Diagnóstico agroflorestal participativo em assentamentos rurais da região de Ribeirão Preto, Estado de São Paulo. Jaguariúna: Embrapa, 2006.

RIBASKI, S. A. G.. Sistemas Silvipastoris: Estratégias para o Desenvolvimento Rural Sustentável para a Metade Sul do Estado do Rio Grande do Sul. Colombo: 2005.
ROSS, S. A.; WESTERFIELD, R. W.; JAFFE, J. F.. Administração Financeira. São Paulo: Atlas, 1995.

SACRAMENTO, C. K.; ANDRADE, R. A.. Cultivo do Rambotã. Revista Brasileira de Fruticultura, Jaboticabal, v.36, n.1, p.79-85, 2014. DOI: http://doi.org/10.1590/0100-2945$\underline{448 / 13}$

SANTANA, A. C.. Elementos de economia, agronegócio e desenvolvimento local. Belém: UFRA, 2005.

SANTOS, G. C.; JARDIM, M. A. G.. Florística e estrutura do estrato arbóreo de uma floresta de várzea no município de Santa Bárbara do Pará, Estado do Pará, Brasil. Acta Amazônica, v.36, n.4, p.437-446, 2006.

SANTOS, S. S., GRZEBIELUCKAS, C.. Sistema Silvipastoril com Eucalipto e Pecuária de Corte: uma Análise de Viabilidade Econômica em uma Propriedade Rural em Mato Grosso/Brasil. Custos e @gronegócio, v.10, n.3, 2014.

SIQUEIRA, D. L.; PEREIRA, W. E.. Planejamento e implantação de pomar. Viçosa: UFV, 2000. SOARES, F. P.; PAIVA, R.; NOGUEIRA, R. C.; OLIVEIRA, L. M.; PAIVA, P. D. O.; SILVA, D. R. G.. Cultivo e usos do Nim (Azadirachta indica A. Juss). Boletim Agropecuário, v.68, p.1-14, 2006.

SOUSA, S. G. A.; WANDELLI, E. V.; COSTA, J. R.; PERIN, R.; FERNANDES, E. C. M.. Potencialidades do Ingazeiro (Inga edulis Mart.) e da glicidia (Gliricida sepium (Jaqcq.) Kunth ex Walp.) como adubos verdes em agroecossistemas. In: REUNIÃO AMAZÔNICA DE AGROECOLOGIA. Anais. Manaus: 2007.

SOUZA, A. A.; BRUNO, R. L. A.; LOPES, K. P.; CARDOSO, G. D.; PEREIRA, W. E.; FILHO, J. C.. Semillas de Spondias tuberosa oriundos de frutos cosechados en cuatro estadios de maturación y almacenadas. Revista Brasileira de Engenharia Agrícola e Ambiental, Campina Grande, v.9, n.3, p.372-378, 2005. DOI: http://doi.org/10.1590/S141543662005000300012

SOUZA, A. N.; OLIVEIRA, A. D.; SCOLFORO, J. R. S.; REZENDE, J. L. P.; MELLO, J. M.. Viabilidade Econômica de um Sistema Agroflorestal. Cerne, Lavras, v.13, n.1, p.96-106, 2007.

SOUZA, M. D.; PERES FILHO, O.; DORVAL, A.. Efeito de extratos naturais de folhas vegetais em Leucoagaricus gongylophorus (Möller) Singer, (Agaricales: Agaricaceae). Ambiência, v.7, n.3, p.461-471, 2011.

VAZ, P.. Sistemas agroflorestais como opção de manejo para microbacias. Informe agropecuário, v.21, p.75-81, 2000.

WOODS, W. I.. Development of anthroposol research. Berlim: 2003.

A CBPC - Companhia Brasileira de Produção Científica (CNPJ: 11.221.422/0001-03) detém os direitos materiais desta publicação. Os direitos referem-se à publicação do trabalho em qualquer parte do mundo, incluindo os direitos às renovações, expansões e disseminações da contribuição, bem como outros direitos subsidiários. Todos os trabalhos publicados eletronicamente poderão posteriormente ser publicados em coletâneas impressas sob coordenação da Sustenere Publishing, da Companhia Brasileira de Produção Científica e seus parceiros autorizados. Os (as) autores (as) preservam os direitos autorais, mas não têm permissão para a publicação da contribuição em outro meio, impresso ou digital, em português ou em tradução. 